\title{
(Des)Conexões Estado-Sociedade no Brasil: Um Estudo Sobre a Experiência de Construção de Cisternas no \\ Semiárido
}

(Dis)Connections Between State and Society in Brazil: A Study on the Experience of Constructing Cisterns in the Semiarid Region

Conexiones Estado-Sociedad en Brasil: Un Estudio Sobre la Experiencia de Construcción de Cis-ternas en el Semiárido

José Raimundo Cordeiro Neto

Doutorado em andamento/Universidade Federal de Pernambuco/UFPE Universidade Federal do Vale do São Francisco - Univasf/Professor Assistente http://lattes.cnpq.br/6756568431205288 http://orcid.org/0000-0002-4345-9239 cordeironneto@gmail.com

Jackeline Amantino de Andrade Doutorado concluído/UFRGS Vínculo Institucional Atual / Cargo: Universidade Federal de Pernambuco (UFPE)/Professora Associada http://lattes.cnpq.br/6859223626901586 http://orcid.org/0000-0002-6451-4049

jackeline.amantino@gmail.com

José Emanuel Medeiros Marinheiro Graduação concluída/Universidade Federal do Vale do São Francisco http://buscatextual.cnpq.br/buscatextual/visualizacv.do?id=K4303325E0 http://orcid.org/0000-0001-9688-6245 emanuel.mm@hotmail.com

Resumo: Renovar a relação Estado-Sociedade no Brasil tem sido assunto em pauta nas últimas décadas. Nesse debate, inserem-se perspectivas teóricas como a Governança Pública e a Gestão Social, com suas devidas particularidades e algumas convergências. Junto à teorização, experiências consideráveis têm sido empreendidas no país por meio de formas colaborativas de gestão entre governos e outros atores sociais. Para refletir sobre esse fenômeno, este trabalho utilizou um design de pesquisa qualitativa, abordando uma experiência dessa natureza no âmbito da política de segurança hídrica no Semiárido brasileiro. A partir desse caso, procura-se evidenciar e discutir formas renovadas de gestão, forjadas na experiência acessada, destacando o provimento de soluções coletivas mediante papel ativo de famílias e organizações locais. Assinala-se, porém, a permanência de restrições desafiantes, como a tendência de, frente às múltiplas lógicas de ação envolvidas, contornar problemas decorrentes por mecanismos que inibem maior engajamento cívico nas ações compartilhadas.

Palavras-chave: Governança Pública; Gestão Social; cisternas; Semiárido brasileiro

\begin{abstract}
Renewing the State-Society relationship in Brazil has been the subject on the agenda in recent decades. In this debate, there are theoretical perspectives such as the Public Governance and Social Management, with their own characteristics and some convergences. Beside the theoretical reflection, considerable experience has been undertaken in the country through collaborative forms of management between government and other social actors. To reflect on this phenomenon, this article made use of a qualitative research model, addressing such experience within the water security policy in the Brazilian semiarid region. From this case, we seek to highlight and discuss renewed ways of management forged in the experience by providing collective solutions through the active role of families and local organizations. It is noted, however, the persistence of challenging constraints such as the tendency to circumvent problems in view of the multiple logics involved, through mechanisms that inhibit the realization of greater civic engagement.
\end{abstract}

Keywords: Public Governance; Social management; cisterns; Brazilian semiarid region.
Resumen: Renovar la relación Estado-Sociedad en Brasil ha sido tema en pauta en las últimas décadas. En ese debate, se insertan perspectivas teóricas como la Gobernanza Pública y la Gestión Social, con sus debidas particularidades y algunas convergencias. Junto a la teorización, experiencias considerables se han emprendido en el país a través de formas colaborativas de gestión entre gobiernos y otros actores sociales. Para reflexionar sobre este fenómeno, este trabajo utilizó un diseño de investigación cualitativa, abordando una experiencia de esa naturaleza en el ámbito de la política de seguridad hídrica en el Semiárido brasileño. A partir de ese caso, se busca evidenciar y discutir formas renovadas de gestión, forjadas en la experiencia accedida, destacando el provecho de soluciones colectivas mediante papel activo de familias y organizaciones locales. Se señala, sin embargo, la permanencia de restricciones desafiantes, como la tendencia de, frente a las múltiples lógicas de acción involucradas, eludir los problemas derivados de mecanismos que inhiben un mayor compromiso cívico en las acciones compartidas.

Palabras clave: Gobernanza Pública; Gestión Social; cisternas; Semiárido brasileño.

Texto completo em português: http://www.apgs.ufv.br Full text in Portuguese: http://www.apgs.ufv.br

\section{Introdução}

O presente artigo discute o desenvolvimento de processos colaborativos entre sociedade civil e administração pública, a partir do estudo de uma experiência brasileira específica, no campo da segurança hídrica de famílias rurais da região Semiárida. Mais precisamente, este trabalho analisa a experiência de construção coletiva de cisternas domiciliares de captação e armazenamento de água no Semiárido, cuja emergência histórica se deu por meio de iniciativas autônomas empreendidas pela sociedade civil e se desenvolveu, durante décadas, por meio das bases associativas próprias de diversos atores sociais e suas organizações não estatais.

Ao início dos anos 2000 , essas iniciativas foram traduzidas em ações na agenda governamental, configurando o que viria a ser conhecido como Programa Um Milhão de Cisternas Rurais (P1MC), conjuntamente formulado e operacionalizado como política pública desde então. Essa experiência destaca-se no contexto nacional, seja pela dimensão do problema hídrico no 
Semiárido e o desafio que ele representa para as políticas públicas (Campos, 2014), seja pela frequente associação da região e do mundo rural brasileiro a padrões perversos na vida política, a comportamentos pouco propensos à cooperação e à gestão coletiva (Lanna, 1995; Cremonese, 2006; Bursztyn \& Chacon, 2011).

Com o propósito de discutir o relacionamento EstadoSociedade no desenvolvimento de formas compartilhadas de gestão, cabe registrar que este trabalho se configurou a partir de duas perspectivas basilares, uma de natureza teórica e outra de caráter metodológico. Em termos teóricos, a discussão realizada apoia-se no debate sobre a relação Estado-Sociedade, no âmbito temático da Gestão Social e da Gestão Pública, concentrando-se, nesta última, nas questões de governança evocadas. A análise, embora com ênfase nos achados empíricos, busca algum suporte nessas áreas disciplinares, assimiladas como condizentes com a experiência pesquisada, que historicamente teve início com atuações independentes da sociedade civil para, mais à frente, constituir um entrelaçamento com a dinâmica estatal.

Compreende-se, aqui, que Gestão Social e Governança Pública, muito embora constituam campos de conhecimentos e práticas específicas, têm, na interface entre elas, elementos pertinentes para se discutirem proposições de uma Gestão Pública ampliada e mais sintonizada com a promoção da cidadania e da democracia. Cada uma a seu modo, essas disciplinas possibilitam questionar o velho dilema entre eficiência e democracia (Loureiro \& Abrucio, 2012) ou entre administração e política (Paula, 2005; Secchi, 2009).

Quanto ao caráter metodológico, por sua vez, cabe destacar a opção pelo emprego da narrativa (Alves \& Blikstein, 2006; Jovchelovitch \& Bauer, 2002) como elemento central na estratégia de investigação. Nesse sentido, o trabalho interpretativo enfatizou o conceito de função de transformação da narrativa (Alves \& Blikstein, 2006), tratando-se, no caso pesquisado, do processo de passagem da construção autônoma de cisternas - pelos atores da sociedade civil e sem a presença do Estado -, para um segundo momento de inserção dessas atividades, em novas bases, no desenho do programa P1MC.

Fundamentando-se na abordagem de Alves e Blikstein (2006), nota-se que a ideia de "função de transformação" é pertinente ao estudo de movimentos como esses, na medida em que se refere a mudanças de condições ou alterações de estado, presentes nos enunciados das histórias coletadas. Além desse alinhamento com a configuração da trajetória estudada, essa opção metodológica está ancorada na compreensão de que os elementos acessados em enredos são esclarecedores para o entendimento de conteúdos e processos, os quais, por sua vez, são dimensões fundamentais no campo das políticas públicas. Conforme Thoenig (2007), toda política pública parte da configuração de um estado assumido como problemático e apresenta um postulado de transformação de uma situação presente para uma situação desejada, por meio da formulação e utilização de meios específicos.
Em termos de sua estrutura, este trabalho está esquematizado em cinco seções. Seguindo esta introdução, a próxima seção aborda questões da literatura em Gestão Social e em Governança Pública, referentes ao fenômeno em tela. Em seguida, é apresentado o percurso metodológico da pesquisa. Na quarta seção são trazidos e discutidos os principais achados do trabalho e, por fim, feitas as considerações mais gerais.

\section{Pensando as Relações Estado-Sociedade no Brasil: abordagens de um campo em transformação}

O aprimoramento das relações Estado-Sociedade, visto como necessário ao enfrentamento das questões coletivas, é tema amplamente debatido, não apenas no âmbito das chamadas big questions da Administração Pública (Behn, 1995; 1998), mas também por diversas outras perspectivas disciplinares. Aqui, dentre as abordagens possíveis, são trazidas discussões do campo da Gestão Social e da Governança Pública, especialmente aquelas voltadas à compreensão do contexto brasileiro.

De antemão, cabe esclarecer que nem a Gestão Social nem a abordagem da Governança Pública constituem narrativas uníssonas, compreendendo, pelo contrário, campos com significativa diversidade de tratamentos teóricos e analíticos (Justen, Moretto Neto, \& Garrido, 2014; Secchi, 2009). Também, embora ambas reflitam em alguma medida sobre o desafio de novas formas de relacionamento entre o Estado e a sociedade, não se pode concebê-las como meramente complementares. Elas possuem distintas filiações epistemológicas, contextos de origem, ênfases e recursos teóricos utilizados, como destacam Alcântara, Pereira e Silva (2015), quando as analisam comparativamente. Nesta seção, contudo, o esforço não é de comparar as abordagens, mas de destacar alguns dos elementos advindos destes campos e que se mostram relevantes para a compreensão da temática discutida e do caso empírico investigado.

\section{Gestão Social}

A elaboração do termo "Gestão Social" tem em Fernando Tenório (1998; 2008; 2009) seu principal autor, e seu contexto de surgimento no Brasil é a década de 1990. O eixo estruturante da argumentação de Tenório (1998) é a contraposição entre Gestão Estratégica e Gestão Social, apoiando-se teoricamente na perspectiva crítica da Escola de Frankfurt. É com Jügen Habermas e sua classificação da ação racional (teleológica, estratégica, normativa, dramatúrgica e comunicativa) que Tenório dialoga mais diretamente, fazendo uso intenso do conceito de ação racional comunicativa. Em suma, a Gestão Estratégica é entendida por ele como aquela na qual a ação racional estratégica é predominante, enquanto que na Gestão Social a ação racional comunicativa conduziria os processos interativos.

Especialmente a partir dos anos 2000, uma rede de pesquisadores em Gestão Social tomou forma (Silva Júnior, 2008; Schommer \& França Filho, 2008) e promoveu uma certa institucionalização desse campo de práticas e de teorias em construção (França Filho, 2008; Cançado, Tenório \& Pereira, 
2011). Nesse movimento, ampliou-se, também, a diversidade de modos pelos quais a Gestão Social é concebida.

De acordo com Justen, Moretto Neto e Garrido (2014), existiriam na literatura três orientações normativas para abordar a Gestão Social. Uma primeira estaria relacionada a processos dialógicos e voltados à emancipação, dentro da linha iniciada por Tenório (1998) e que define a Gestão Social como "um processo de tomada de decisão coletiva, não hierárquico, baseado na democracia e no interesse coletivo dos participantes" (Cançado, Pereira, \& Tenório, 2015, p. 15). Por sua vez, a orientação normativa adotada por França Filho (2008) busca caracterizar a Gestão Social como "um modo próprio de gestão das organizações da sociedade civil, localizadas na esfera pública não-estatal" (Justen, Moretto Neto, \& Garrido, 2014, p. 240). Nesse sentido, o autor trata da lógica da ação organizacional na Gestão Social como elemento distintivo, cujo caráter "pretende subordinar as lógicas instrumentais a outras lógicas mais sociais, políticas, culturais ou ecológicas" (França Filho, 2008, p. 30). Finalmente, uma terceira orientação seria identificada no trabalho de Fischer (2002), que caracteriza a Gestão Social como um "sistema de governança" do desenvolvimento social, conformado por bases híbridas na relação Estado, sociedade e mercado, numa "ação coletiva gerenciada" e "traduzida em desenhos organizacionais complexos" (Fischer, 2002, p. 23). Tais redes de parcerias dariam forma a estruturas descentralizadas e participativas, utilizadas como ferramentas "para alcançar enfim um bem coletivamente planejado, viável e sustentável a médio e longo prazo" (Gondim; Fischer; \& Melo, 2006, p. 4).

Para Justen, Moretto Neto e Garrido (2014, p. 241), essas diferentes orientações evidenciam que não há nessa temática "uma narrativa uniforme e homogênea", o que pode levar a Gestão Social a ser entendida "como um não conceito". Deve-se destacar, no entanto, o motivo pelo qual ela tem sido constantemente utilizada nas últimas décadas, isto é, para "revelar formas de gestão coletiva" (Freitas, Freitas \& Ferreira, 2016, p. 285). Nas palavras de Schommer e França Filho (2008), a trajetória da Gestão Social deveria ser entendida como permanente construção de um processo de inovação, não como um produto acabado.

Mesmo diante da diversidade de abordagens do campo, podese compreender que, especialmente quando trata da relação Estado-Sociedade, boa parte da literatura em Gestão Social é explícita em assumir o estudo desse tema a partir da perspectiva dos atores não-estatais da sociedade civil e suas formas de lidar com os problemas referentes à vida em sociedade. Assim, Tenório (1998) propõe mesmo um esforço analítico que inverta as preocupações tradicionalmente centradas numa perspectiva tecnicista e estatal, advogando pela ênfase no polo SociedadeEstado. França Filho (2008), ao seu turno, também procura esclarecer que embora a chamada "questão social" seja corriqueiramente tratada no âmbito do setor público, lidar com os problemas da coletividade nunca foi exclusividade deste, sendo necessário dar ênfase às diversas formas de manifestação do fenômeno associativo, especialmente aquele empreendido pelas organizações da sociedade civil, com suas lógicas próprias de atuação.

Essas considerações ressaltam o protagonismo dos atores não-estatais nas questões levantadas pelo campo e na sua forma de conceber os processos de mudança (Alcântara, Pereira, \& Silva, 2015; Cançado, Tenório, \& Pereira, 2011). Na abordagem da Gestão Social do desenvolvimento ou terceira orientação, como classificam Justen, Moretto Neto e Garrido (2014), as organizações estatais parecem ganhar um lugar mais destacado na análise, em comparação com as outras duas orientações. Porém, mesmo ali, a ênfase está nas noções de hibridização e interorganizações envolvidas na gestão de processos de desenvolvimento social (Fischer, 2002), denotando a horizontalidade das relações como elemento central para a diluição do poder, em vez de enfatizar a priori o protagonismo de qualquer ator, seja do Estado, do mercado ou da sociedade. Porém, é sempre válido o alerta de Pinho (2010) e Pinho e Santos (2015), de que "não adianta fazer uma construção teórica com um alto grau de desenvolvimento democrático sem refletir sobre as dificuldades estruturais resultantes da nossa formação social" (Pinho \& Santos, 2015, p. 274). Isto é, não se pode ignorar a fragilidade democrática brasileira e seus aspectos delegativos, bem como as continuidades e enlaces entre o patrimonialismo tradicional e a recente construção democrática no país.

A Gestão Social incorpora numa de suas principais vertentes, importante registrar, uma concepção de espaço público que precisa aqui ser tomada adequadamente. Nesse campo, compreende-se que o interesse público estatal está baseado em prescrições constitucionais e legais típicos das ciências jurídicas, em especial do direito administrativo, diferindo de um interesse de natureza distinta que caracterizaria o espaço público como tal (Oliveira, 2012). Assim, essa compreensão aproxima-se do conceito de esfera pública em Jurgen Habermas, caracterizada como mediadora das relações Estado e sociedade (Oliveira, Cançado, \& Pereira, 2010), na medida em que se constitui em "espaço intersubjetivo comunicativo no qual as pessoas tematizam as suas inquietações por meio do entendimento mútuo" (Tenório, 2008). Nessa perspectiva, é a dialogicidade que permite o exercício do interesse público social, de modo que a Gestão Pública seja orientada pela Gestão Social (Cançado, Tenório, \& Pereira, 2011; Tenório, 2008). Nessas bases, Tenório (2009, p. 3) advoga por uma gestão republicana intrínseca à Gestão Social, quando há "uma preocupação com a justiça social, com o interesse pelo bem comum e não com os interesses privados".

Sob essa perspectiva, prevaleceria a racionalidade comunicativa no espaço público orientado pela Gestão Social, proporcionando o exercício de uma gestão pública ampliada (Tenório, 2008; 2009). Nessa gestão pública ampliada, explicitamente, a lógica sociopolítica e cultural sobressairia, em detrimento de imperativos instrumentais e técnicos pertinentes à lógica da burocracia e do gerencialismo, conforme sugerido por França Filho (2008) e por Paula (2005). Porém, ao contrário de uma eventual ênfase na distinção entre áreas disciplinares que essas considerações possam sugerir, Tenório (2009, p. 57) 
adverte que "o importante não é diferenciar gestão pública de gestão social, mas resgatar a função básica da administração pública [...]. Gestão social seria um adjetivo da gestão pública, não o seu substituto".

No que pese a presença desses delineamentos gerais que permitem compreender determinadas temáticas centrais à Gestão Social, as diversidades de concepções desse campo devem ser devidamente levadas em conta. Por um lado, há conceituações de Gestão Social que perpassam a mencionada proposição de uma esfera pública mediadora do interesse público-social, conforme Oliveira (2012); Cançado; Tenório e Pereira (2011); Cançado; Pereira e Tenório (2015); Paula (2005); e Tenório (1998; 2008; 2009). Por outro lado, a Gestão Social também é concebida como um conjunto de práticas oriundas de organizações vinculadas à sociedade civil e direcionadas ao combate da pobreza, à inclusão social e à solidariedade, dentro de ações orientadas ao desenvolvimento social (Fischer, 2002; Gondim, Fischer, \& Melo, 2006; França Filho, 2008).

Diante da discussão acima exposta, seria plausível indagar em que medida a capacidade dialógica inerente à esfera pública habermasiana, presente na Gestão Social, aproximar-se-ia de questões debatidas entre autores mais vinculados à Administração Pública, a exemplo da ideia do público não-estatal presente em movimentos de reforma do Estado, como a ensaiada no caso brasileiro. Tal questionamento indicaria a compreensão de que ambas as concepções assumem que o Estado não monopolizaria nem esgotaria o interesse público na busca pelo bem comum. Todavia, no que pese essa aproximação, é preciso discernir o modo como as relações Estado-Sociedade são tomadas no debate mais vinculado à área de Administração Pública, aqui discutido pela ótica do campo denominado por "Governança Pública".

\section{Governança Pública}

No contexto brasileiro, o debate sobre Governança Pública está, em grande parte, associado aos propósitos de reforma do Estado, especialmente ao movimento reformista promovido a partir de meados dos anos de 1990. Discursivamente sintonizado com as perspectivas de redefinição do papel do Estado e de implementação do gerencialismo (Bento, 2003; Diniz, 2007), esse movimento colocou em relevo "novas formas de gestão, fortemente orientadas pela melhoria do desempenho do setor público" (Abrucio, 2007, p. 71).

Nesse movimento, significativa centralidade foi dada ao instrumento de "contratos de gestão" entre o denominado "núcleo estratégico" do Estado e as chamadas "organizações sociais" (entidades de direito privado, com fins não lucrativos, representantes do setor público não-estatal). Especialmente, essa seria uma das principais medidas de "inovação dos instrumentos de política social" (Presidência da República, 1995, p. 60), com o intuito de atender aos cidadãos mediante uma governança ampliada ou "capacidade administrativa de governar com efetividade e eficiência” (Presidência da República, 1995, p. 45).
Conforme esclarece Azevedo (1999, p. 131), nessa perspectiva a governança não se limitaria "à capacidade administrativa do Estado e à maior ou menor eficácia da máquina estatal", mas vincular-se-ia também ao "sistema de intermediação de interesses". Contudo, as limitações desse mesmo gerencialismo são substanciais, conforme Paula (2005), para quem os mecanismos de governança presentes na proposta de reforma seriam insuficientes para um efetivo compartilhamento do poder decisório. Como contraponto, a autora elabora sua argumentação a partir da análise de experiências de participação social, a exemplo do Orçamento Participativo, dos Conselhos Gestores de Políticas Públicas e dos Fóruns temáticos, que se multiplicaram pelo Brasil nas últimas décadas. Embora ainda localizadas e fragmentárias, essas experiências justificariam a construção de novos arranjos que privilegiassem a dimensão sociopolítica nos processos de tomada de decisão na Gestão Pública, em vez das dimensões institucional-administrativa e econômico-financeira. Ou, como destacou Motta (2013), seriam processos para propiciar a realização do poder comunitário, pelo processo de ativação de novas competências e interligações com o sistema político, em vez da inserção limitada criticada por Paula (2005).

Apesar dessa associação no contexto brasileiro entre reforma gerencial do Estado e Governança Pública, autores como Kissler e Heidemann (2006) e Secchi (2009) mostram que esta última não está necessariamente associada àquele movimento. Como apontam os mesmos autores, em boa parte da literatura, Governança Pública compreende uma perspectiva de superação dos limites observados no movimento gerencialista.

Na discussão sobre a emergência internacional de programas de reforma administrativa, Kissler e Heidemann (2006) concordam que tal movimento geralmente apresentou mais avanços no tratamento dos problemas administrativos do que no fortalecimento democrático, pela maior ênfase em aspectos de desempenho do que na democratização do processo de formulação de políticas. Para eles, a governança se propõe como novo modo de relação Estado-Sociedade, porém se caracterizaria ainda enquanto um campo incerto, sem um conceito único, mas apenas "diferentes pontos de partida para uma nova estruturação do Estado e suas instituições [...], por um lado, e as organizações privadas, com e sem fins lucrativos, bem como os atores da sociedade civil [...], por outro" (Kissler \& Heidemann, 2006, p. 480).

Secchi (2009), por sua vez, reconhece no debate sobre Governança Pública elementos de continuidade e de descontinuidade em relação às proposições do movimento gerencialista. $\mathrm{Na}$ sua análise, o autor toma Governança na perspectiva das discussões do campo da administração pública e da ciência política. Para ele, o conceito faz referência a um paradigma relacional na Gestão Pública, o qual pressupõe o pluralismo como valor positivo, "no sentido que diferentes atores têm, ou deveriam ter, o direito de influenciar a construção das políticas públicas" (Secchi, 2009, p. 358). O autor aponta que a 
preocupação com a função administrativa do controle representa um elemento de continuidade entre o gerencialismo e a Governança Pública (entendido, nesta, como controle social), embora esta última contribua para destacar a função direção, pela ênfase em processos de liderança e de coordenação necessários aos mecanismos horizontais de cooperação entre Estado e demais atores sociais. Por outro lado, Secchi (2009) também assinala que a separação entre administração e política, presente em modelos gerencialistas, é suavizada no paradigma da Governança Pública, por evocar processos de compartilhamento do poder decisório. Nesse sentido, "significa um resgate da política dentro da administração pública, diminuindo a importância de critérios técnicos nos processos de decisão e um reforço de mecanismos participativos de deliberação na esfera pública" (Secchi, 2009, p. 359).

Essa forma de conceber a Governança Pública, desse modo, mostra-se mais alinhada ao propósito de fortalecer a democracia como valor em si, para além da ênfase em questões de desempenho e eficiência. Afastando-se das teses que advogavam pelo insulamento do Estado como condição necessária à efetividade das políticas públicas, a Governança Pública passa a enfatizar aquilo que Evans (1993) chamaria de estruturas sociais circundantes e o papel das interações entre os atores sociais para o aperfeiçoamento destas mesmas políticas e para a promoção da cidadania (Loureiro \& Abrucio, 2012; Peters \& Pierre, 1998; Thoenig, 2007). Preocupação semelhante também aparece em Evans (1996) e Ostrom (1996), autores cujas teorizações, respectivamente, creditaram aos regimes sinérgicos e de coprodução capacidades em aprimorar processos colaborativos público-privados para o gerenciamento das demandas coletivas.

Nas palavras de Thoenig (2007), movimentos como esse da governança estariam relacionados à compreensão da dimensão pública como fenômeno social, visto que o Estado "não detêm o controle monopolístico do manejo dos assuntos públicos" (p. 13) e que "políticas públicas não são apenas políticas de organizações públicas" (p. 23). Ainda assim, Secchi (2009) mostra que a primazia do Estado como ator central nos processos de Governança Pública é um dos pontos de contestação presentes na literatura, havendo correntes que advogam por tomá-lo como protagonista nas redes de relacionamento, enquanto outros autores assumem a completa horizontalidade nessas redes.

Esse despontar da governança e de temáticas a ela relacionadas revela tendência já indicada por Diniz (1996), na ampliação de uma capacidade governativa orientada à criação e desenvolvimento de canais institucionalizados, de efetivos controle e participação social. De tais canais, espera-se a possibilidade de envolvimento mais direto da sociedade nas atividades decisória e de implementação de políticas públicas (Diniz, 1996), de maneira a reduzir a distância entre a democracia formal e a democracia substantiva, combatendo os deficits de inclusão social, de capacidade estatal e de accountability (Diniz, 2007). Ou seja, tratase da emergência de uma Gestão Pública direcionada a atender fortemente o interesse público, centrada no cidadão e orientada por uma cidadania engajada e crítica, de acordo com as proposições de Denhardt (2012). A capacidade gerencial estaria associada, consequentemente, à capacidade de accountability societal, voltada aos aspectos inerentes de democratização das relações Estado e sociedade, concebida como republicanização do espaço público (Carneiro, 2004). Na mesma linha de raciocínio, Keinert (2000) teria identificado, no contexto brasileiro de análises da administração pública, um processo de substituição do paradigma do público enquanto estatal pelo paradigma do público enquanto interesse público, ao qual corresponderiam a bases sociocêntricas na relação Estado-Sociedade, em vez do caráter estadocêntrico costumeiramente assumido.

Há, porém, muitos desafios ainda não respondidos, quanto à efetividade da governança em compor novas formas políticas de gestão e, com isso, constituir um terceiro pilar democrático, ao lado dos mecanismos de representação e de democracia direta (Kissler \& Heidemann, 2006). Ademais, como anteriormente referido a partir de Secchi (2009), a ausência de narrativas únicas e conceitos cristalizados nesse campo pode ser tomada como aspecto que instiga tratar a temática a partir de contornos empíricos configurados em contextos concretos de interação Estado-Sociedade. Compreende-se aqui que esse esforço pode auxiliar a compreensão de processos de gestão compartilhada a partir de relações interinstitucionais, naquilo que Kooiman (2002) caracteriza como gestão colaborativa orientada para a canalização de forças societais. Em outras palavras, esse entendimento permite considerar a coprodução de políticas públicas entre Estado e sociedade, a partir da relação múltipla de atores e vislumbrando em que medida a incorporação da sociedade civil possibilita elevar a reflexibilidade da gestão pública (Andrade, 2004; Grau, 1998).

Ante essa breve discussão, fundamenta-se no presente artigo a opção por discutir a relação Estado-Sociedade em formas colaborativas de gestão, priorizando-se a análise empírica de experiências desenvolvidas. Ainda que procurando fazer uso dos debates aqui pontuados e de argumentações neles desenvolvidas, não se pretende eleger um modelo analítico prévio que conduza a análise, mas empregar tais categorias teóricas como orientações gerais para a investigação.

\section{Procedimentos metodológicos}

Em decorrência do propósito de discutir o relacionamento Estado-Sociedade, no âmbito das questões de colaboração ou produção conjunta das políticas, levantadas por movimentos como a Governança Pública e nas teorizações sobre Gestão Social, o trabalho apresentado é resultante de pesquisa que adotou o estudo de caso como estratégia de investigação. Consoante com tal abordagem, delimitou-se a experiência do Semiárido brasileiro no processo histórico de construção de cisternas domiciliares rurais como caso a ser estudado, isto é, como sistema limitado (Stake, 2005; 1995), sobre o qual o trabalho se debruçaria. Ainda, uma microrregião específica do Semiárido foi escolhida para o aprofundamento da pesquisa, qual seja, a microrregião de Juazeiro/BA'. 
De natureza qualitativa, o presente estudo adota a perspectiva de situar o tópico em estudo (relacionamento Estado-Sociedade) a partir da orientação de discussões teóricas, sem, contudo, impor um arcabouço pré-definido de construto e variáveis (Gephart, 2004; Creswell, 2007). Em síntese, as discussões tecidas na seção anterior forneceram o foco analítico com o qual o estudo de caso foi conduzido.

Num esforço de descrição e de interpretação do fenômeno investigado, foram organizados dois corpora de pesquisa para o processo de coleta de dados, diversificando as fontes de evidência sob os critérios de homogeneidade, relevância e sincronia, e buscando ampliar as representações dos atores sociais, acessadas na investigação (Bauer \& Aarts, 2002). O primeiro corpus foi constituído de textos diversos, coletados em fontes documentais distintas (estatutos de organizações, editais públicos, termos de convênio de programas, projetos, atas, relatórios de desempenho e prestação de contas, materiais de divulgação, cartilhas de orientação, textos jornalísticos, entre outras). De natureza apenas documental (homogeneidade), a constituição dessa coleção de textos também atentou para o princípio da relevância (todo item precisou ter relação com o foco temático: a experiência de construção de cisternas na região estudada). Quanto ao princípio da sincronia, cabe ressaltar que todos os textos que compuseram o corpus foram produzidos no período pós-1999, ano em que se constituiu o Fórum Articulação no Semiárido (ASA), representando um marco no movimento associativo das organizações envolvidas com a iniciativa pesquisada. Tanto o documento fundacional do Fórum ASA quanto diversos registros da política pública em operacionalização foram reunidos nesse primeiro agrupamento, cuja análise possibilitou uma familiarização inicial dos pesquisadores com o caso em estudo e proporcionou as ferramentas para a segunda fase da coleta de dados.

A segunda fase da investigação foi iniciada, por sua vez, pela construção do segundo corpus, este composto por narrativas de atores diversos, participantes do fenômeno estudado e que foram identificados, sobretudo, pelas informações oriundas das fontes documentais anteriormente citadas. As narrativas em questão foram produzidas a partir de entrevistas semiestruturadas, realizadas com o intuito de acessar as expressões daqueles atores sobre a experiência pesquisada, por meio das histórias que necessariamente entrelaçaram processos individuais e sociais em seus enredos (Jovchelovitch \& Bauer, 2002). Elementos extraídos da análise do primeiro corpus auxiliaram na identificação de questões exmanentes sobre a temática em foco (preocupações dos pesquisadores e expressas na linguagem destes), as quais possibilitaram a elaboração de tópicos-guia para a condução das entrevistas. Buscou-se, além disso, conduzir as conversações sob a forma de entrevistas narrativas, nas quais os atores eram solicitados a descrever sua experiência com o processo de construção de cisternas em comunidades rurais (elemento gerador). Ao pesquisador, coube observar e estimular, quando foi o caso, a transformação das questões exmanentes, inicialmente formuladas, em questões imanentes (expressas na linguagem dos entrevistados).

Nesse segundo corpus, apenas entrevistas (num total de 22) foram reunidas (homogeneidade), registradas em áudio e, em seguida, transcritas. Todos os entrevistados correspondem a atores envolvidos no processo de construção de cisternas, cujas trajetórias pessoais se intercruzam com a experiência investigada (princípio da relevância quanto ao foco temático). Compreendendo, como apontam Bauer e Aarts (2002), que o corpus deve ser homogêneo quanto à natureza do dado levantado e heterogêneo quanto às fontes acessadas, quatro estratos distintos de atores sociais e suas narrativas foram abordados nas entrevistas: i) indivíduos participantes da representação nacional do Fórum Asa Brasil e/ou da Unidade Gestora Central (AP1MC) (cinco entrevistas); ii) membros da Unidade Gestora Microrregional (UGM) na microrregião estudada (seis entrevistas); iii) membros das comissões municipais do P1MC na microrregião (cinco entrevistas); e iv) membros de famílias participantes do programa (seis entrevistas). Em termos do critério de sincronicidade, os relatos produzidos foram delimitados em narrativas que iniciaram com as primeiras ações dos atores em experiências de construção de cisternas em comunidades rurais, até suas atividades mais recentes no âmbito do Programa P1MC.

As transcrições das entrevistas foram analisadas a partir das orientações de Jovchelovitch e Bauer (2002) e Alves e Blikstein (2006), especialmente sob os princípios de "formação de enredos" e da ênfase nas "funções de transformação" presentes nas narrações. Como resultado desse trabalho, a seção que segue apresenta a interpretação a que se chegou, enfatizando uma função de transformação específica, isto é, o processo de passagem da construção autônoma de cisternas - pelos atores da sociedade civil e sem a presença do Estado -, para um segundo momento, de inserção dessas atividades, em novas bases, no desenho do programa $\mathrm{P} 1 \mathrm{MC}$.

\section{A experiência de construção de cisternas no Semiárido: destacando aspectos no processo de mudança}

Pelas limitações de formato do presente trabalho, apresentarse-ão nesta seção os eixos centrais do processo estudado, compreendidos na pesquisa. Tais eixos serão trazidos à discussão sob a forma de categorias advindas da interpretação, agrupando aspectos destacados pela análise, em vez de apresentar o detalhamento do enredo produzido a partir das trajetórias individuais produzidas e analisadas. Cabe dizer, ademais, que essa categorização privilegiou questões emergentes na pesquisa, associadas à noção de centros temáticos nos quais os atores fixam pontos de relevância, dentre os muitos elementos que dão sentido de totalidade às suas narrativas (Jovchelovitch \& Bauer, 2002). Não se categorizou, dessa forma, pela relação com construtos estabelecidos a priori, como anteriormente assinalado.

Uma breve síntese da experiência, a partir do caso estudado 
Muito embora tenha sido a partir do início dos anos 2000 que a experiência de construção de cisternas no Semiárido passou a integrar o rol de políticas públicas, iniciativas dessa natureza têm um histórico bem mais extenso na região. Desde no mínimo três décadas atrás, a partir de dinâmicas territoriais diversas e em várias partes do Semiárido, organizações não governamentais mobilizavam atores locais e extra-locais para o empreendimento de ações no campo da agricultura familiar, de modo relativamente isolado entre elas. Dessas ações, muitas contemplaram a construção de reservatórios d'água e outras tecnologias, para o enfrentamento coletivo do problema do deficit hídrico e da consequente insuficiência de água para consumo humano.

A ausência do poder público durante grande parte da trajetória estudada, vale ressaltar, é uma das razões pelas quais apenas a perspectiva da governança pública e seu frequente foco em ações protagonizadas pelo Estado (Alcântara, Pereira \& Silva, 2015; Secchi, 2009) mostra-se insuficiente para refletir sobre essa configuração, sendo necessário buscar formas mais sociocêntricas de análise (Keinert, 2000), para ampliar a compreensão do fenômeno. $\mathrm{Na}$ pesquisa, partes das narrativas produzidas apontam esse processo autônomo da sociedade civil como antecedente relevante para o posterior processo de formulação do $\mathrm{P} 1 \mathrm{MC}$ nos moldes de uma política para toda a região:

Existia cisterna espalhada pelo Nordeste inteiro. Aí que a gente começou a descobrir. Em todos os estados tinha construção de cisternas (Membro de UGM 1).

O nosso trabalho era sempre... partia de uma experiência que o povo já tem. (Membro de UGM 3).

Especificamente na microrregião focalizada, a particularidade da dinâmica local está associada às práticas da Igreja Católica, por meio da Diocese de Juazeiro/BA, desde a segunda metade da década de 1970. Inicialmente atuante no campo da defesa de direitos sociais de trabalhadores rurais e no estímulo à organização comunitária deles, a Diocese passou, na década de 1980, a se debruçar sobre o problema do abastecimento hídrico das comunidades. É interessante observar como os déficits da atuação estatal no contexto pesquisado, bem como os déficits democráticos, típicos das sociedades latino-americanas (Diniz, 2007), faziam com que as demandas coletivas não tivessem outro modo de enfrentamento que não por meio de mecanismos de auto-organização, tal qual genericamente abordado por França Filho (2008). Numa das entrevistas, uma afiliada a um sindicato rural local narrou o seguinte:

... a gente tinha assim muito apoio [...] . O padre mesmo deu assim o maior apoio pra que as pessoas criassem associações no interior, tudo... foi com o apoio da Diocese (Membro de UGL 2).

Na trajetória desse modo iniciada, destaca-se a produção de reservatórios hídricos em localidades de diversos municípios da microrregião de Juazeiro/BA. Entretanto, essas iniciativas mostravam-se insuficientes em quantidade (escala reduzida, pela escassez de recursos disponíveis para construí-las, abrangendo poucas famílias) e em qualidade (água quase sempre imprópria para consumo humano, em virtude das fontes de coleta, e problemas técnicos com as construções).
[A gente] não sabia o que fazer... A questão era essa [...] até a gente chegar na perspectiva da cisterna (Membro de UGM 4).

Ela passa [a cisterna] a dar um sentido prático a tudo isso, para não ficar só nas discussões [...] Passa a modificar a realidade (Membro de UGL 3).

Nos anos 1990, novos eventos marcaram a experiência estudada, no sentido de expandir sua abrangência. Um primeiro deles é referente ao esforço dos atores locais em aprovarem projetos de lei, junto a legislativos municipais, que instituíssem planos de abastecimento hídrico, contemplando a construção de cisternas domiciliares. De cinco municípios onde isso ocorreu, mediante discussão das propostas e coleta de milhares de assinaturas da população, apenas em um a iniciativa foi efetivada e, ainda assim, de modo distinto do que fora proposto. Esse ponto demonstra uma clara tentativa de intersecção com a dinâmica estatal e os limites da democracia representativa para a intermediação de interesses, como destacado em Tenório (1998; 2008), que também enfatiza a relevância de mecanismos de participação direta, acessados, nesse caso, via proposição de leis de iniciativa popular, visando contornar os problemas da inserção limitada, criticada por Paula (2005).

[...] pra colher as assinaturas [de apoio aos projetos de lei] precisava todo um trabalho de explicação pro povo e tal... então isso serviu pro pessoal perceber que o que estava faltando ali [...]. O que eles achavam é que não tinha solução pra isso, mas tinha solução sim (Membro de UGM $6)$.

Um segundo conjunto marcante de eventos consistiu numa campanha que visava obter doações, locais e de outras regiões, para ampliar a prática de construção de cisternas. Referindo-se a essas experiências, os trechos de narrativa abaixo são esclarecedores:

A campanha tinha o objetivo de denunciar a seca aqui na região [...] era uma coisa [a seca] que toda vida teve, o que não tinha era políticas públicas. $E$ aí a gente aproveitou e disse: 'não, nós temos que ter um instrumento né... pedagógico, que chame a atenção, então a gente utilizou a cisterna (Membro de UGM 1).

Ao final da década de 1990, após significativo acúmulo de aprendizados, os atores locais participaram de diversas articulações regionais, mediadas por fóruns que reuniam organizações de várias partes do Semiárido, visando trocar experiências sobre o enfrentamento dos problemas da região. Esse processo culminou na formação do Fórum Articulação do Semiárido (Fórum Asa), coletivo da sociedade civil constituído de centenas de organizações desse campo, dos vários estados da região.

... e a Asa se configurou exatamente por causa desse trabalho, a junção de todas essas informações, né? De todas essas problemáticas (Membro de UGL 5).

Desse modo, essa trajetória permitiu a composição de dinâmicas sociais e aprendizados que, alguns anos depois, possibilitaram o êxito da luta pela inserção da experiência na pauta das políticas públicas para o Semiárido, via articulação do Fórum Asa, protagonizada junto ao Governo Federal. Inicialmente, 
ao começar os anos 2000, a construção de cisternas contou com o financiamento de projeto-piloto, inserido no orçamento do Ministério do Meio Ambiente (MMA). A partir de 2003, as ações foram ampliadas e transferidas para o âmbito da política coordenada pelo Ministério Extraordinário de Segurança Alimentar (Mesa), posteriormente transformado em Ministério do Desenvolvimento Social (MDS).

Com essa mudança, a microrregião de Juazeiro/BA e demais microrregiões do Semiárido, antes atuantes em iniciativas de pouco alcance em termos de famílias envolvidas e com variadas formas organizacionais e técnicas, passaram a atuar a partir de um desenho único de política e de uma tecnologia uniforme de construção dos reservatórios. Para tanto, uma Unidade Gestora Central (UGC) foi constituída a partir do Fórum Asa e denominada de Associação Gestora do Programa Um Milhão de Cisternas (AP1MC). Conveniando com o Governo Federal para o aporte necessário de recursos, a AP1MC passou a firmar Termos de Cooperação com outras organizações da sociedade civil, selecionadas por meio de editais específicos. Essas últimas constituem, no desenho da política, as Unidades Gestoras Microrregionais (UGMs) e, via de regra, correspondem a uma organização enraizada em cada território, afiliada ao Fórum Asa e com experiência histórica no desenvolvimento de iniciativas junto à agricultura familiar.

Como se procurou demonstrar, há muitas razões para se conceber o caso estudado enquanto originalmente fundamentado em formas específicas de manifestação do fenômeno associativo via mecanismos de auto-organização da própria sociedade (França Filho, 2008) e posteriormente inserido em um contexto híbrido (Fischer, 2002; Gondim, Fischer e Melo, 2006) de relações Estado-Sociedade. Nesse sentido, as mudanças que ocorrem no decorrer dessa trajetória permitem discutir como a inserção da experiência numa perspectiva de governança "mais ampla" (Diniz, 1998; 2007; Keinert, 2000; Secchi, 2009) estão associadas a alterações no modus operandi das ações, especialmente em termos de sua lógica particular de atuação e de interação entre os participantes (Tenório, 1998; 2008; França Filho, 2008). É sobre os aspectos de mudança na trajetória, associados a esse ponto de transformação das práticas dos atores, que as subseções que seguem tratarão.

Um primeiro aspecto da mudança: a configuração organizacional

A dinâmica organizacional da experiência estudada difere bastante quando se observa sua configuração previamente à implementação do P1MC e posteriormente a esse evento. Nesse sentido, observam-se mudanças ocasionadas pela entrada de novos atores no campo das ações e pela formação de novas relações entre os participantes. As narrativas apontam que a presença direta da Administração Pública no escopo do caso cria interações até então inexistentes ou pouco frequentes, sobretudo na relação das organizações locais com Ministérios e suas secretarias e com órgãos de controle, como o Tribunal de Contas da União (TCU). Também, a mudança ocorre por meio de interações mais intensas entre as próprias organizações que compõem o Fórum Asa, agora ocupadas num esforço de ação coletiva que precisa ser coordenado em abrangência regional.

Se previamente ao programa as vinculações necessárias se davam junto a organizações internacionais de ajuda humanitária ou buscando parcerias da Igreja Católica em diversos países, por exemplo, agora a colaboração com o Estado, representado pelo Governo Federal, predomina nas articulações. O pluralismo advogado tanto pela perspectiva da gestão social (Tenório, 1998; 2010; Fischer, 2002; Cançado, Tenório, \& Pereira, 2011; Paula, 2005) quanto pela abordagem da governança pública (Kissler \& Heidemann, 2006; Secchi, 2009; Alcântara, Pereira \& Silva, 2015) parece expandir-se a partir da transformação ocorrida, tanto em termos da quantidade de atores participantes quanto da intensidade das interações, conformando um rede mais ampla e novos contornos das relações.

No plano local, entretanto, foi interessante observar que as relações das organizações ligadas à agricultura familiar com as prefeituras e legislativos municipais permaneceu marcada por significativo distanciamento, fruto de conflitos anteriores e de certa incompatibilidade entre as práticas envolvidas. Essa incompatibilidade parece guardar relação com a coexistência de dinâmicas organizacionais diversas na gestão das políticas públicas brasileiras, na medida em que as mudanças promovem acúmulos de valores e práticas em vez de completa superação de formas tradicionais como o patrimonialismo ou o modelo burocrático (Secchi, 2009; Motta, 2013). Nesse sentido, no caso estudado, as organizações da sociedade civil adotaram um posicionamento de proteger a experiência da intervenção de políticos locais, sob o argumento de que estes poderiam conduzir o programa para o campo do clientelismo e do patrimonialismo, como indicam os recortes de falas abaixo:

... vamo mudar de conversa rapaz... O negócio de prefeito aqui... é chumbo grosso! (gargalhada) (Membro de Família Participante 2).

Nesses espaços das comissões municipais, caso exista algum membro da prefeitura, ele não tem voto. É justamente pra neutralizar a ideia da cultura do Semiárido de que por exemplo a cisterna teria que ir prum canto só porque um político, fulano de tal, tá querendo que tal comunidade seja beneficiada. E não é nossa lógica, entendeu? (Membro de UGC 3)

Internamente, no âmbito do próprio coletivo de organizações sociais, hierarquias antes inexistentes passam a se consolidar na coordenação das ações. A AP1MC, de certo modo, passa a se confundir com a coordenação nacional do Fórum Asa e a representar certa autoridade decisória sobre a dinâmica das operações. Ainda que desde 1999 a Asa já articulasse organizações diversas, observou-se que foi necessário estabelecer relações mais estáveis e formalizar parcerias antes mantidas informalmente.

Essas comissões elas já tem uma bandeira de luta delas.. que se reúnem independente. Agora quando o projeto de cisterna chega, impulsionou também pra que essas comissões se reunissem mais (Membro de UGL, 3). 
Mas, isso vai ser base para esse relacionamento nas unidades gestoras né? Quem é que vai tá nas Unidades Gestoras? É o pessoal do trabalho de base, é o pessoal das comunidades, é o pessoal dos sindicatos, das Ongs, das pastorais, é essa turma que vai tá gerenciando isso também (Membro de UGM 4).

No plano local (da microrregião), ainda que as instâncias previstas no programa sejam formadas pelos atores territoriais antes atuantes nas experiências autônomas, novos componentes passam a configurar as relações, na medida em que maior formalidade é exigida. Ilustra esse ponto o fato de que, em cada município do caso estudado, foram as "comissões de água" formadas à época da proposição de projetos aos legislativos municipais - que se tornaram as Unidades Gestoras Locais requeridas pelo desenho do programai".

Então muita coisa que, que... nós tínhamos como experiência e tal, se concretizando, começou a fazer parte do projeto (Membro de UGM 6).

eu tenho que pegar um animador [profissional que atua no trabalho de campo] que já conheça os carreros, que já tenha contato com a comissão, com as famílias (Membro de UGL 2).

Esse processo envolveu, consequentemente, o emprego das bases locais de mobilização para a constituição das instâncias de organização necessárias ao Programa. Todavia, isso não representou apenas uma renomeação dos grupos, implicando também uma mudança no modus operandi pelo qual as atividades eram desenvolvidas. Assim, há novidades no processo organizativo para atender à gestão do novo formato da ação coletiva, o que implica novas combinações entre horizontalidades e verticalidades nas redes de relacionamento entre os atores, para tomar os termos de Fischer (2002) e Gondim, Fischer e Melo (2006). A forma como o poder flui nessas redes, uma preocupação das autoras citadas, pode ser um ponto central para o entendimento da transformação ocorrida, na medida em que interfere nas possibilidades de exercício dialógico da capacidade decisória (Tenório, 1998; 2010; Paula, 2005; Oliveira, 2012) e na qualidade da efetiva participação dos atores no desenvolvimento da política pública (Thoenig, 2007; Diniz, 1998; Secchi, 2009).

Um segundo aspecto: uma nova dinâmica de gerenciamento

As narrativas produzidas durante a pesquisa apontam para uma mudança significativa do processo de gerenciamento da construção de cisternas, ocasionada quando da emergência do P1MC. Procedimentos, escalas, prazos e metas, associados à natureza pública dos recursos utilizados, passam a contrastar com a experiência anterior, na qual cada localidade atendia particularidades contextuais e atuava em escalas reduzidas, com prazos e metas mais flexivelmente pactuados.

Esse aspecto toma contornos mais factuais quando alguns exemplos são detalhados. No caso estudado, foi frequente nas entrevistas a demonstração de que, antes do $\mathrm{P} 1 \mathrm{MC}$, quando obtidos recursos para construção de cisternas, as organizações optavam por envolver famílias com maior exposição ao problema hídrico e em cuja composição familiar predominassem mulheres, crianças e/ou idosos. Isso implicava selecionar famílias, ainda que na área rural de um mesmo município, com residências muitas vezes localizadas a grandes distâncias entre elas, resultando num significativo tempo necessário para as operações logísticas, seja na mobilização e convencimento das famílias a serem envolvidas, seja no transporte de materiais e pessoas para possibilitar as construções. Isso, porém, implicava algo que não pôde ser mantido após o P1MC:

Esses projetos com recursos públicos são engessados, onde existe um monte de normas e critérios, onde muitas familias, sobretudo, às vezes, as mais carentes são excluídas do processo (Membro de UGL, 6).

Com o P1MC, veio a necessidade de agilizar as operações, em escala agora maior, para atendimento aos prazos estabelecidos. A forma de atender a esses elementos foi, em cada município, a concentração geográfica das operações, o que significa atender a localidades específicas conforme prioridade estabelecida e abandonar o parâmetro anteriormente preponderante.

Todos precisavam! [...] Mas tem uns que precisavam mais... E aí, por exemplo, famílias que estavam lá afastadas poderiam ficar para uma outra etapa. Às vezes era a mais necessitada, acabava ficando pra uma etapa posterior (Membro de UGM, 5).

Também, se antes as organizações podiam distribuir temporalmente suas atividades em adequação às condições socioculturais e climáticas locais, isso já não era possível com o advento do $\mathrm{P} 1 \mathrm{MC}$. Os cronogramas de liberação de recursos para as construções, fora da interferência dos atores locais, demandavam que as operações fossem postas em curso independente de o momento específico favorecer ou comprometer as atividades. Antes do $\mathrm{P} 1 \mathrm{MC}$, a experiência se pautava por concentrar as construções após os períodos chuvosos de cada ano, quando as estradas de acesso às zonas rurais já se encontravam transitáveis; as famílias rurais, especialmente os componentes masculinos, já haviam encerrado a maior parte do trabalho em suas lavouras e poderiam se dedicar a auxiliar na tarefa de construção das cisternas; pequenos lagos e riachos das comunidades ainda forneciam água e areia com facilidade, insumos básicos para o trabalho. Essa lógica de gerenciamento, tal qual ocorreu na dimensão espacial, ficaria impossibilitada ante os requisitos advindos da Gestão Pública.

Trabalhava-se feito escravo (Membro de UGM, 5).

Nossos projetos, nós temos metas, nós temos um ano pra poder realizar um projeto de 1.800 cisternas. Um ano! Então eu não posso perder dois, três meses... (Membro de $U G L, 2)$.

Também foi curioso $o$ aparecimento nas narrativas da referência a problemas envolvendo a gestão de compras de insumos por meio de procedimentos similares às licitações nas organizações públicas. Especificamente, uma das entrevistadas descreveu a falta de confiança com a qual empreendimentos locais do segmento de materiais de construção receberam a 
proposta de fazer ofertas de produtos junto à gestão microrregional. Segundo a entrevistada, havia um descrédito nas práticas da Administração Pública, o que desfavorecia encontrar o fornecimento dos itens necessários:

Eles [os comerciantes] têm em mente que quando você entrega uma cotação, que já existe um ganhador (Membro de UGL, 5).

Ainda, a questão da escala das atividades representou um empecilho quando houve, a partir do ano de 2010, uma aparente constatação por parte do Governo Federal de que o desempenho do programa seguia numa velocidade de construções inferior à desejada. Com isso, o Governo recorreu, paralelamente, à aquisição e instalação na zona rural semiárida de cisternas industriais prontas feitas em polietileno (construídas em fábricas, em série, sem participação das famílias). O Fórum Asa mobilizouse contra o avanço dessa prática, considerada pelo coletivo de organizações como um retrocesso na tecnologia social de mobilização promovida pelo $\mathrm{P} 1 \mathrm{MC}$, bem como por julgar a tecnologia de fabricação inadequada às condições físicoclimáticas do Semiárido. A prática paralela de instalação das cisternas de polietileno, contudo, não foi eliminada, muito embora o P1MC não tenha sido descontinuado.

Há elementos novos nessa dinâmica de gerenciamento, dessa forma, a demonstrar que o equacionamento entre as questões de ordem econômico-financeira, institucional-administrativa e sociopolíticas difere a partir da transformação analisada. A ênfase em questões de desempenho parece ter se dado e sombreado dimensões da lógica própria da auto-organização anterior. $O$ interesse público, como abordado pelas organizações da sociedade civil em suas experiências autônomas, já não pôde ser concebido da mesma forma quando da parceria com o Estado, evidenciando as distinções evocadas por Oliveira (2012) e Oliveira, Cançado \& Pereira (2010) na diferenciação daquilo que entendem como interesse público estatal.

Um terceiro aspecto: a forma de envolvimento das famílias e organizações locais

Antes do P1MC, a atuação das organizações participantes, junto aos agricultores familiares, suas associações, sindicatos e outras formas organizativas, havia sedimentado um processo histórico de confiança, que foi crucial para a mudança estudada. Sem isso, muito raramente se teria obtido a mesma predisposição das famílias, nem de suas organizações associativas, em participarem das atividades. Na narrativa de um membro de uma família participante, a fonte dessa relação de confiança é expressa no trecho abaixo:

Aí eu digo: mas se você vê quem mais tem trabalho prestado aqui, são as associações junto com os comunitários, porque infelizmente, político não tem trabalho prestado aqui não! (Membro de Família Participante, 4).

Deve-se esclarecer que, para o desempenho das ações em cada microrregião, o quadro de pessoal administrativo, contratado mediante recursos do $\mathrm{P} 1 \mathrm{MC}$, restringe-se a cinco profissionais: três técnicos de campo, dois assistentes administrativos e um gestor geral. Dessa forma, as lideranças envolvidas no trabalho das Unidades Gestoras Locais e junto às comunidades rurais de cada município se envolvem voluntariamente. Também, as famílias contempladas com a construção de uma cisterna em sua residência não acompanham passivamente a construção e instalação do equipamento. Elas assumem parte relevante do trabalho e dos custos, na medida em que se responsabilizam pela escavação do local em que o reservatório será construído e pelo fornecimento da mão-de-obra de auxílio ao pedreiro que conduzirá a fabricação da cisterna. Ainda, cada família participa de cursos sobre a gestão de recursos hídricos, fornecidos pelo Programa.

Desde a primeira cisterna, todas elas tinha participação da família ... [...] Num se falava em política pública naquela época. [...] Qualquer obra que chegasse numa comunidade era tido assim como uma esmola. E a gente assim com a cisterna, tentou envolver desde o início as comunidades (Membro de UGM, 5).

Nessas narrativas, sobressaem-se elementos que sinalizam o acesso pelo Estado aos mecanismos locais de legitimidade, reciprocidade e confiança (Thoenig, 2007; Kissler \& Heidemann, 2006; Peters \& Pierre, 1998), que permitem minimizar deficits históricos de inclusão social e de capacidade estatal de implementação (Diniz, 2007), aproximando-se de um complexo arranjo de governança (Fischer, 2002; Gondim; Fischer \& Melo, 2006). Além disso, trata-se de um fator importante para a performance econômica da política pública, evitando maiores custos das operações, aspecto geralmente destacado em muito da literatura sobre os arranjos coprodutivos (Ostrom, 1996; Behn, 1995; Bento, 2003). Observa-se, todavia, que a natureza do envolvimento de famílias e de coletivos diversos, na experiência estudada, muda substancialmente com a formalização da política pública. A colaboração que esse elemento permite passa a ser acessada como recurso para o atendimento às diretrizes e prazos do programa, mas perde possibilidades que eram exercitadas anteriormente.

Exemplificam esse ponto dois eventos marcantes nas narrativas. O primeiro é decorrente da exigência, no $\mathrm{P} 1 \mathrm{MC}$, de que um domicílio deveria ter um telhado com dimensão mínima de $40 \mathrm{~m}^{2}$ para viabilizar a instalação da cisterna. Ocorre que, segundo os entrevistados, as famílias mais vulneráveis muitas vezes não atendem a esse critério. Assim, em casos específicos, redes de cooperação existentes no território foram acessadas para a construção conjunta de acréscimos no telhado de residências, a fim de que algumas famílias pudessem participar do programa.

Quando a gente tinha esses recursos que não era recursos públicos [estatais], né, a gente trabalhava de acordo com a necessidade da família. Hoje, não. Hoje, além da necessidade, mas nem tanto a necessidade, mas de acordo com os critérios que são impostos (Membro de UGM, 6).

O segundo evento, por sua vez, ilustra como o envolvimento comunitário pode ter suas possibilidades de cooperação restringidas pela emergência da política pública. Antes do P1MC, era prática na microrregião estudada que, em cada residência 
onde uma cisterna fosse construída, a família pudesse retribuir financeiramente parte dos custos envolvidos, ao longo de um período de tempo acordado com as organizações envolvidas. Esse reembolso facultativo, de parte do valor de cada cisterna, possibilitava a formação de um fundo de recursos, localmente denominado de Fundo Rotativo Solidário. Com ele, era possível a construção de cisternas adicionais sobre o número inicialmente viabilizado pelos recursos disponíveis. Além da participação das famílias no processo de construção da cisterna, essa participação financeira fortalecia o caráter ativo delas no processo para muito além de figurar como mero público-alvo.

Não existia prazo e nem prestação fixa, mas você ia devolvendo dentro da sua condição financeira, da sua consciência, para que outras pessoas pudessem ter a cisterna (Membro de UGM, 2).

Essa prática, contudo, foi inviabilizada logo no início do P1MC, por determinação dos órgãos de controle. Tradicionalmente fundamentado em termos jurídicos, esse controle geralmente focaliza a legitimação pelos procedimentos, em vez de pelos resultados, numa tensão que evidencia a carência de novos instrumentos jurídicos para potencializar as novas ferramentas gerenciais em suas propriedades socialmente desejáveis (Bento, 2003). Ao fim, na experiência com as cisternas, prevaleceu o entendimento de que o público contemplado, mediante orçamento federal, não poderia ser induzido à contraprestação nos termos do Fundo Rotativo Solidário.

Independente do governo, as coisas funcionavam de forma mais comunitária, depois o governo não aceitava mais devolução, não aceitava o fundo rotativo... (Membro de UGL, 2).

Tal como ocorreu nesse caso, outros exemplos de redução da margem de autonomia e do engajamento da sociedade civil podem ser acessados nas narrativas, indicando que a experiência não apenas retrata conexões com o Estado, mas também desconexões consideráveis. Produzir conjuntamente bens públicos não é algo que emerge espontaneamente, requerendo engenhosidade dos participantes para contornar entraves diversos (Ostrom, 1996). Assim, a pluralidade aludida pela literatura passa a demandar não apenas maior capacidade de coordenação frente ao número ampliado de atores no âmbito da política pública, mas também o equacionamento de eventuais divergências entre eles por meio do empreendimento de regimes organizacionais imaginativos que efetivem as sinergias latentes entre os grupos (Evans, 1996). Discordâncias essas advindas, geralmente, de uma paralela variedade de lógicas organizacionais de atuação e modos de gestão, divergindo, dentre outros aspectos, no exercício da racionalidade (França Filho, 2008; Bento, 2003; Tenório, 1998) e no modo de compreender os interesses coletivos (Oliveira, 2012; Oliveira, Cançado \& Pereira, 2010).

\section{(Des)Conexões Estado-Sociedade: delineando algumas considerações}

A busca por novos formatos de relacionamento EstadoSociedade, que atendam simultaneamente ao princípio do fortalecimento democrático e ao objetivo de aperfeiçoar o gerenciamento das políticas públicas, está em pauta na sociedade brasileira desde no mínimo a década de 1990.

Nesse contexto, abordagens como a Gestão Social e a Governança Pública têm sido crescentemente evocadas para a reflexão sobre a teoria e a prática no campo dessa discussão. Paralelamente, experiências como a apresentada neste trabalho, ao tempo em que permitem observar o desenvolvimento de processos efetivos de gestão colaborativa entre Estado e sociedade, também expressam dificuldades consideráveis para o avanço na dimensão sociopolítica e no exercício compartilhado do poder por meio dessas formas de gerenciamento. Essa restrição indica o quanto experiências como essa ainda se encontram aquém das propriedades assumidas como desejáveis na relação Estado-Sociedade, tanto pela literatura em Gestão Social que se fundamenta na dialogicidade do agir comunicativo quanto por aquela vertente da Governança Pública que se pretende mais democratizante, conciliando melhor as dimensões política e administrativa da gestão.

Como é notório no caso da construção de cisternas no Semiárido, as relações múltiplas entre atores, com suas lógicas distintas de atuação, passam a ser um elemento mais central na forma de governança definida para o Programa P1MC. Todavia, há mais evidências de que tal processo se desenvolva primordialmente em sua função de garantir conjuntamente o provimento de serviços e bens coletivos, num cenário histórico de marcante ausência do Estado - só recentemente mitigada -, do que na sua potencialidade de republicanização do espaço público. Não parece se tratar de um processo de ampliação da gestão pública na direção defendida por Tenório (2009), isto é, via orientação das políticas públicas pela lógica da gestão social. Por outro lado, o modo peculiar de emergência dessa política pública garante, em sua configuração, significativo avanço perante as convencionais mazelas da interação público-privado no Brasil, com maior espaço para lógicas não tecnocráticas de gestão e para a participação das organizações e cidadãos locais.

Por conseguinte, não se trata de negar que experiências como - P1MC expressem mudanças valorosas no padrão de relacionamento Estado-Sociedade, possibilitando uma dinâmica de atenção às particularidades loco-regionais, de um modo que raramente seria obtido pelo modelo convencional. Não obstante, é também preciso assinalar lacunas, que permanecem e restringem um atendimento mais completo àqueles princípios de fortalecimento da cidadania, advogados tanto pelos movimentos pró-governança pública, quanto pela abordagem da Gestão Social. Esse aspecto assume um relevo especial, considerando que a experiência estudada emerge numa ação protagonizada por atores loco-regionais, inserindo demandas na agenda governamental e participando diretamente da formulação e da implementação de políticas sem, entretanto, subverter a lógica predominante da ação estatal.

Ao que parece, velhos trade-offs entre democracia e eficiência e entre política e administração continuam a desafiar a constituição de arranjos de interação mais virtuosos. Arranjos esses nos quais imperativos como expansão da escala de 
operações, melhoria de desempenho gerencial e garantia do uso transparente dos recursos públicos não sejam alcançados em detrimento de objetivos igualmente importantes, como a efetivação do potencial de engajamento da sociedade na ação coletiva e a maior abertura para formas inovadoras de enfrentamento dos problemas direcionados ao interesse público.

\section{Referências}

Abrucio, F. L (2007). Trajetória recente da gestão pública brasileira: um balanço crítico e a renovação da agenda de reformas. Revista de Administração Pública. Edição Especial Comemorativa. p. 67-86, 2007.

Alcântara, V. C.; Pereira, J. R.; Silva, E. A. F. (2015). Gestão Social e Governança Pública: Aproximacões e (De)Limitacões Teórico-Conceituais. Revista de Ciências da Administração. v. 17, Edição Especial, p. 11-29.

Alves, M. A., Blikstein, I. (2006). Análise da narrativa. In: Godoi, C. K.; Bandeira-de-Melo, R.; Silva, A. B. (Orgs.) Pesquisa qualitativa em estudos organizacionais: paradigmas, estratégias e métodos. São Paulo: Saraiva.

Andrade, J. A. (2004). O espaço público como uma rede de atores: a formação da política de erradicação do trabalho infantil no Brasil. 2004. 219 p. Tese (Doutorado em Administração) - PPGA/UFRGS, Porto Alegre.

Articulação do Semiárido Brasileiro (2016). P1MC: Programa Um Milhão de Cisternas. Disponivel em: http://www.asabrasil.org.br/acoes/p1mc. Acesso em 30/05/2016.

Azevedo, S. (1999). Reforma do Estado e mudança institucional: variáveis exógenas e endógenas. In: Melo, M. A. (org.) Reforma do Estado e Mudança Institucional no Brasil. Recife: FUNDAJ/Ed. Massangana, 1999. pp. 111-142.

Bauer, M. W., \& Aarts, B. A. (2002). Construção do corpus: um princípio para a coleta de dados qualitativos. In: Bauer, M. W., \& Gaskell, G. (orgs). Pesquisa qualitativa com texto, imagem e som: um manual prático. Petrópolis, RJ. Vozes.

Behn, R. D.. (1995). The Big Questions of Public Management. Public Administration Review 55(4): 313-324

Behn, R. D. (1998). O novo paradigma da gestão pública e a busca da accountability democrática. Revista do Serviço Público v. 49, n. 4, pg. 5-45.

Bento, L. V. (2003) Governança e governabilidade na reforma do Estado: entre eficiência e democratização. Barueri, SP: Manole.

Bursztyn, M., \& Chacon, S. S. (2011). Ligações Perigosas: Proteção Social e Clientelismo no Semiárido Nordestino. Estudos Sociedade e Agricultura, v. 19, p. 30-61.

Campos, J. N. B. (2014). Secas e políticas públicas no Semiárido: ideias, pensadores e períodos. Estudos Avançados, v. 28, n. 82, p. 65-88.

Cançado, A. C., Pereira, J. R., Tenório, F. G. (2015). Fundamentos Teóricos da Gestão Social. Desenvolvimento Regional em debate, v. 5, p. 4-19.

Cançado, A. C., Tenório, F. G., \& Pereira, J. R. (2011). Gestão social: reflexões teóricas e conceituais. Cadernos Ebape, v. 9, n. 3, p. 681-703.

Carneiro, C. B. L. (2004). Governança e accountability: algumas notas introdutórias. Texto para Discussão 13, Fundação João Pinheiro. Belo Horizonte.

Cremonese, D. (2006). Insolidarismo e cordialidade: uma análise das mazelas políticas do Brasil. In: Baquero, M., \& Cremonese, D. (orgs). Capital social: teoria e prática. ljuí: Ed. Unijuí.

Creswell, J. W. (2007). Qualitative inquiry and research design: choosing among five approaches. Thousand Oaks: Sage Publications.

Denhardt, R. B. (2012). Teorias da administração pública. São Paulo: Cengage Learning. Diniz, E. (2007). O pós-Consenso de Washington: globalização, Estado e governabilidade reexaminadas. In: Diniz, E. (org.). Globalização, Estado e Desenvolvimento: dilemas do Brasil no novo milênio. Rio de Janeiro, Editora FGV.

Diniz, E. (1996). Em busca de um novo paradigma: a reforma do Estado no Brasil nos anos 90. São Paulo em Perspectiva. 10 (4), p. 13-26.

Evans, P. (1996). Government action, social capital and development: reviewing the evidence on synergy. World Development. Vol 24, $n^{\circ} 6$. pp 1073-1087.

Evans, P. (1993). O Estado como problema e solução. Lua Nova n $28-29$ São Paulo.

Fischer, T. (2002). Poderes locais, desenvolvimento e gestão: introdução a uma agenda. In: Fischer, T. (Org.). Gestão Social e Poderes Locais: marcos teóricos e avaliação. Salvador-BA. Casa da Qualidade

Freitas, A. F., Freitas, A. F., \& Ferreira, M.A.M. (2016). Gestão social como projeto político e prática discursiva. Cadernos Ebape. V. 14, n. 2, p. 279-292.

França Filho, G. C. (2008). Definindo Gestão Social. In: Silva Junior, J. T.; Mâish, R. T.; Cançado, A. C.; Schoomer, P. C. Gestão Social: práticas em debate, teorias em construção. Fortaleza: Imprensa Universitária.

Gephart, R. (2004). Qualitative research and the Academy of Management Journal. Academy of Management Journal, v. 47, n. 4, p. 454-462.

Gondim, S., Fischer, T., \& Melo, V. P. (2006). Formação em Gestão Social: um Olhar Crítico sobre uma Experiência de Pós-graduação. In: Fischer, T., Roesch, S., \& Melo, V. Critico sobre uma Experiência de Pós-graduação. In: Fischer, T., Roesch, S., \& Melo, V.
P.. (Org.). Gestão do Desenvolvimento Territorial e Residência Social. Salvador: Edufba. Grau, N. C. (1998). Repensando o público através da sociedade. Rio de Janeiro: Revan/ENAP.

Instituto Brasileiro de Geografia e Estatística (2016). Cidades@. Disponível em: http://www.cidades.ibge.gov.br/xtras/home.php?lang=. Acesso em 30/05/2016.

Jovchelovich, S., \& Bauer, M. (2002). Entrevista narrativa. In: Bauer, M. W., \& Gaskell, G. (orgs). Pesquisa qualitativa com texto, imagem e som: um manual prático. Petrópolis, RJ: Vozes.

Justen, C. E., Moretto Neto, L., \& Garrido, P. O. (2014). Para além da dupla consciência: gestão social e as antessalas epistemológicas. Cadernos Ebape. v. 12, n. 2, p. 241-251. Keinert, T. M. M. (2000). Administração pública no Brasil: crises e mudanças de paradigmas. São Paulo: Annablume: Fapesp.
Kissler, L., \& Heidemann, F. G. (2006). Governança pública: novo modelo regulatório para as relações entre Estado, mercado e sociedade? Revista de Administração Pública. 40 (3): 479-499.

Kooiman, J. (2002). Governance: a social-political perspective. In: Grote, J. R., \& Gbikpi, B. (eds.). Participatory Governance: political and societal implications. Opladen: B. (eds.). Participatory Governar.
Leske/Budrich., 2002, pp. 71-96.

Lanna, M. P. D. (1995). A dívida divina: troca e patronagem no Nordeste brasileiro. Campinas, SP: Ed. Unicamp.

Loureiro, M. R., \& Abrucio, F. L. (2012). Democracia e eficiência: a difícil relação entre política e economia no debate contemporâneo. Revista de Economia Política, v. 32, p. 615-615.

Motta, P. R. (2013). O estado da arte da gestão pública. RAE, v. 53, p. 82-90

Oliveira, V. A. R. (2012). Interesse público, gestão pública e gestão social: significados e conexões. Lavras, UFLA. (Tese de Doutorado)

Oliveira, V. A. R., Cançado, A. C., \& Pereira, J. R. (2010). Gestão social e esfera pública: aproximações teórico-conceituais. Cadernos Ebape. V. 8, n. 4 ,p .613-626.

Ostrom, E. (1996). Crossing the great divide: coproduction, synergy, and development. World Development. Vol 24, n .6. pp. 1073-1087.

Paula, A. P. P. (2005). Por uma nova gestão pública: limites e potencialidades da experiência contemporânea. 1. ed. Rio de Janeiro: Editora da Fundação Getúlio Vargas. $204 p$

Peters, B. G., \& Pierre, J. (1998). Governance Without Government? Rethinking Public Administration. Journal of Public Administration Research and Theory. 8:2. pp: 223-243.

Presidência da República do Brasil. (1995). Plano Diretor da Reforma do Aparelho do Estado. Brasília

Pinho, J. A. G. de., \& Santos, M. E. P. (2015). Gestão social: uma análise crítica de experiências brasileiras. Revista do Serviço Público, v. 62, p. 93-115.

Pinho, J. A. G. de. (2010). Gestão Social: conceituando e discutindo os limites e possibilidades reais na sociedade brasileira. In: Rigo, A. S., Silva Junior, J. T., Schoomer, P. C., \& Cançado, A. C. Gestão Social e Políticas Públicas de Desenvolvimento: ações, articulações e agenda. Petrolina-PE, Univasf

Secchi, L. (2009). Modelos organizacionais e reformas da administração pública. Revista de Administração Pública, v. 43, n. 2, p. 347-369.

Schommer, P. C., \& França Filho, G. C. (2008). Gestão social e aprendizagem em comunidades de prática: interações conceituais e possiveis decorrências em processos de formação. In: Silva Junior, J. T., Mâish, R. T., Cançado, A. C., \& Schommer, P. C. Gestão Social: práticas em debate, teorias em construção. Fortaleza: Imprensa Universitária.

Silva Júnior, J. T. et al. (2008). Gestão Social: práticas em debate, teorias em construção. Fortaleza: Imprensa Universitária.

Stake, R. E. (2005). Qualitative case studies. In: Dezin, N., \& Lincoln, Y. S. (eds). The sage handbook of qualitative research. London: Sage.

Stake, R. E. (1995). The art of case studies research. London/New Delhi, Sage Publications.

Tenório, F. G. (2009). Gestão social: uma réplica. Revista ADM.Made. v. 13, n. 2, p. 1-4. Tenório, F. G. (2008). (Re)visitando o conceito de Gestão Social. In: Silva Junior, J. T., Mâish, R. T., Cançado, A. C., \& Schommer, P. C. Gestão Social: práticas em debate, teorias em construção. Fortaleza: Imprensa Universitária.

Tenório, F. G. (1998). Gestão social: uma perspectiva conceitual. Revista de Administração Pública. RJ: vol. 32. $n^{\circ} 5$

Thoenig, J-C. (2007). Recuperando a ênfase na dimensão pública dos estudos organizacionais. Revista de Administração Pública. Edição Especial Comemorativa. p. 9 36.

i A construção de cisternas rurais, no âmbito do Programa P1MC, é operacionalizada por meio de uma divisão microrregional do território Semiárido. A microrregião escolhida para o estudo localiza-se ao Norte do estado da Bahia, na fronteira com os estados de Piauí e Pernambuco, compreende oito municípios e uma população de 498,3 mil habitantes, conforme estimativa feita para o ano de 2015, pelo IBGE (2016). Como os demais 1.135 municípios do Semiárido, essa microrregião se caracteriza por reduzidas médias anuais de precipitação pluviométrica, presença de déficits hídricos e significativo risco de ocorrência de secas. Nessa microrregião, mais especificamente no município de Sobradinho, foi construída a cisterna $\mathrm{n}^{\circ} 1$ do P1MC, no ano de 2000. Segundo o Fórum ASA Brasil, até 29/05/2016, 585,62 mil cisternas foram construídas em todo o Semiárido através do programa (Articulação do Semiárido [ASA], 2016).

ii Em cada município, as Unidades Gestoras Locais desempenham tarefas específicas: o levantamento e cadastro prévio de famílias a serem atendidas; decidem sobre a alocação dos recursos financeiros; selecionam as residências a serem contempladas, conforme os critérios do programa; auxiliam na contratação de serviços e na compra dos insumos necessários participam da sensibilização e capacitação das famílias, para a utilização adequada dos equipamentos a serem instalados, dentre outras tarefas (ASA, 2016). 